Jurnal Keperawatan Silampari

Volume 4, Nomor 2, Juni 2021

e-ISSN: 2581-1975

p-ISSN: 2597-7482

DOI: https://doi.org/10.31539/jks.v4i2.1945

\title{
ANALISIS KEBUTUHAN TENAGA PERAWAT DI RSUD dr. SOEDONO MADIUN
}

\author{
Ayu Nur Malasari ${ }^{1}$, Nyoman Anita Damayanti $^{2}$, Kantrey Sugiarto $^{3}$ \\ Universitas Airlangga ${ }^{1,2}$ \\ Universitas Soerjo Ngawi ${ }^{3}$ \\ ayu.nur.malasari-2018@fkm.unair.ac.id ${ }^{1}$
}

\begin{abstract}
ABSTRAK
Penelitian ini bertujuan sebagai bahan pertimbangan dalam perencanaan sumber daya manusia terutama dibidang keperawatan untuk mendapatkan tenaga yang efektif dan efisien. Metode penelitian ini adalah studi literatur dari beberapa teori penghitungan jumlah tenaga keperawatan menggunakan metode penghitungan metode formula Nina dan metode Ilyas. Hasil penelitian, berdasarkan penghitungan metode Formula Nina, jumlah perawat yang diperlukan RSUD dr. Soedono Madiun dengan tingkat BOR $66,19 \%$ adalah 775 orang. Berdasarkan penghitungan metode Formula Ilyas, jumlah tenaga perawat yang diperlukan RSUD dr. Soedono Madiun dengan tingkat BOR 66,19\% adalah 219 orang. Simpulan, terdapat perbedaan hasil penghitungan kebutuhan tenaga perawat pada Metode Formula Nina dan Metode Formula Ilyas. Hasil penghitungan dari metode Formula Nina yang mendekati dengan kebutuhan tenaga perawat RSUD dr. Soedono Madiun saat ini.
\end{abstract}

Kata Kunci: BOR, Penghitungan Kebutuhan Tenaga, Perencanaan Perawat

\section{ABSTRACT}

This study aims to materialize human resource planning, especially in nursing, to get an effective and efficient workforce. This research method is a literature study of several theories of calculating the number of nursing staff using the Nina formula method and the Ilyas method. The results of the study, based on the calculation of the Nina Formula method, the number of nurses needed by dr. Soedono Madiun with a BOR rate of $66.19 \%$ is 775 people. Based on the analysis of the Ilyas Formula method, the number of nurses required by dr. Soedono Madiun with a BOR rate of $66.19 \%$ is 219 people. In conclusion, there are differences in calculating the need for nurses in the Nina Formula Method and the Ilyas Formula Method. The calculation results from the Nina Formula method are close to the need for nurses at dr. Soedono Madiun at this time.

Keywords: BOR, Calculation of Personnel Requirements, Nurse Planning

\section{PENDAHULUAN}

Berdasarkan Keputusan Menkokesra Nomor 53 Tahun 2013 tentang Rencana Pengembangan Tenaga Kesehatan Tahun 2011 - 2025, target rasio perawat terhadap jumlah penduduk pada tahun 2019 adalah 180 per 100.000 penduduk. Namun pada tahun 2016, rasio perawat secara nasional adalah 113,4 per 100.000 penduduk, menunjukkan bahwa jumlah tenaga perawat masih jauh dari target tahun 2019 
(Kementerian Kesehatan RI, 2017). Sehingga secara nasional, Indonesia masih mengalami kekurangan tenaga perawat dalam pelaksanaan layanan kesehatan.

Perawat merupakan profesi kesehatan yang harus dilibatkan dalam pencapaian pembangunan kesehatan. Profesi ini menjadi salah satu tolak ukur demi tercapainya kesehatan yang berkualitas (Padila et al., 2018). Penelitian Rizky et al., (2018) diketahui terdapat hubungan yang signifikan dengan korelasi negatof antara jumlah tenaga perawat dengan beban kerja perawat pelaksana. Hal ini berarti semakin kecil jumlah tenaga perawatnya maka semakin besar beban kerjanya. Hal ini sejalan dengan penelitian Nurjanah et al., (2017) dimana perawat dianggap produktif bila mampu menyelesaikan $80 \%$ dari beban kerjanya. Selain itu, penghitungan tenaga perawat memiliki banyak metode, dan untuk tenaga perawat di fasilitas kesehatan milik pemerintah terdapat standar yang telah ditentukan dalam Permenkes RI Nomor 33 Tahun 2015. Hasil penelitian Rizcarachmakurnia et al., (2017) diketahui bahwa jumlah tenaga perawat di Puskesmas Poncol telah sesuai dengan standar, namun berdasarkan hasil penghitungan dan wawancara mendalam dengan menguraikan kegiatan yang dilakukan diketahui jumlah perawat masih kurang 1 orang. Kurangnya tenaga perawat dapat menurunkan mutu asuhan keperawatan karena beban kerja berlebih, sehingga pendayagunaan tenaga perawat di fasilitas kesehatan belum optimal dalam menyelenggarakan praktik asuhan keperawatan yang efektif.

Kondisi ini dialami pula oleh RSUD dr. Soedono Madiun, sesuai dengan hasil Survey Kepuasan Karyawan Tahun 2018, dimana unsur Kesesuaian Jumlah Pegawai dengan Formasi yang Dibutuhkan mendapatkan penilaian indeks kepuasan terendah yaitu 2,68 dari skala 4,00. Dari hasil survey yang dilakukan dengan wawancara langsung menggunakan kuisioner, didapatkan hasil bahwa alasan terbesar ketidaksesuaian jumlah pegawai tersebut dikarenakan perbandingan jumlah pegawai tidak sesuai dengan beban kerja, dan adapula yang menyampaikan bahwa pasien dan jumlah perawat tidak sebanding.

Berdasarkan data di atas, maka diperlukan penghitungan kebutuhan tenaga perawat yang sesuai untuk mencapai pelayanan keperawatan yang bermutu baik kuantitas maupun kualitasnya. Fasilitas kesehatan milik pemerintah banyak melakukan penghitungan berdasarkan Permenkes RI Nomor 33 Tahun 2015, sehingga perlu dilakukan penghitungan dengan menggunakan metode lain sebagai perbandingan untuk mendapatkan hasil yang sesuai dengan kondisi dan kebutuhan fasilitas kesehatan tersebut. Untuk itu penelitian ini akan membandingkan metode penghitungan kebutuhan tenaga perawat yang menggunakan Bed Occupation Rate (BOR) sebagai dasar penghitungan, agar mewakili beban kerja dari tenaga perawat di RSUD dr. Soedono Madiun.

\section{METODE PENELITIAN}

Jenis penelitian ini adalah studi literatur yang berisi uraian tentang teori penghitungan kebutuhan tenaga perawat. Metode penghitungan yang digunakan adalah yang menggunakan nilai BOR sebagai dasar penghitungan yaitu Metode Formula Nina dan Metode Formula Ilyas. Kemudian akan dibandingkan untuk melihat jumlah kebutuhan tenaga perawat yang paling mendekati dari kebutuhan tenaga RSUD dr. Soedono Madiun. 


\section{HASIL PENELITIAN}

Pada penelitian ini, peneliti melakukan penghitungan kebutuhan tenaga perawat dengan membandingkan 2 (dua) metode yang menggunakan indikator BOR sebagai salah satu unsur penghitungan yang dapat menggambarkan beban kerja dari perawat di RSUD dr. Soedono Madiun. Berdasarkan data Rawat Inap RSUD dr. Soedono Madiun dari tahun 2015 s.d tahun 2017 terjadi peningkatan jumlah pasien yang dirawat, sebagaimana tabel di bawah ini :

Tabel. 1

Data Rawat Inap RSUD dr. Soedono Madiun

Tahun 2015 s.d Tahun 2017

\begin{tabular}{clccc}
\hline NO & \multicolumn{1}{c}{ Uraian } & Tahun 2015 & Tahun 2016 & Tahun 2017 \\
\hline 1. & Jumlah Penderita Masuk & 16.550 & 19.924 & 20.326 \\
2 & Jumlah Hari Perawatan & 73.264 & 78.884 & 83.836 \\
& (Penderita dirawat ) & & & \\
3 & Jumlah Keluar Hidup & 16.137 & 17.188 & 18.086 \\
4 & Jumlah Kematian & 1.964 & 2.032 & 1.985 \\
\hline 5 & Pemanfaatan TT Perawatan: & & & \\
& Jumlah Tempat Tidur (TT) & 343 & 324 & 347 \\
& ALOS (6-9 hr) & 5 & 5 & 5 \\
& BOR (60\%-85\%) & 58,67 & 66.52 & 66,19 \\
& BTO (40-50 kali) & 53 & 59 & 58 \\
& TOI (1-3 hr) & 3 & 2 & 2 \\
& & & & 58,34 \\
\hline 6 & Angka Kematian: & 52,87 & 56.61 & 98,90 \\
\hline
\end{tabular}

Berdasarkan tabel 1 diketahui bahwa terjadi peningkatan kunjungan rawat inap dari tahun 2015 hingga tahun 2017. Hal ini diikuti dengan penambahan jumlah tempat tidur, ditunjukkan dengan nilai BOR dan nilai Bed Turn Over (BTO) yang cukup tinggi melebihi standar yang ada. Seperti diketahui bahwa BTO adalah jumlah pemanfaatan tempat tidur pasien dalam satu waktu tertentu atau berapa sering tempat tidur dipakai dalam satu periode. Nilai BTO yang tinggi memicu terjadinya gangguan pada mutu pelayanan suatu rumah sakit terutama dalam memberikan rasa aman dan nyaman terhadap pasien. Untuk itu dengan adanya peningkatan jumlah kunjungan akan menambah beban kerja perawat, perlu dilakukan penghitungan tenaga perawat yang dapat memenuhi kebutuhan layanan kesehatan di RSUD dr. Soedono Madiun. Sehingga dilakukan penghitungan kebutuhan tenaga perawat berdasarkan nilai BOR dengan menggunakan metode sebagai berikut:

\section{Metode Formula Nina}

Metode ini menggunakan lima tahapan untuk memperkirakan jumlah tenaga yang dibutuhkan untuk profesi perawat, dengan melakukan penghitungan 5 (lima) tahap. Tahap pertama, menentukan nilai A yaitu jumlah jam asuhan keperawatan pasien selama 24 jam setiap pasien, dan rata-rata nilai A sebesar 4 jam/hari. Tahap kedua menentukan nilai B yaitu jumlah rerata jam asuhan keperawatan bagi seluruh pasien selama satu hari. Nilai B didapatkan dengan mengalikan nilai A dengan jumlah tempat tidur, sehingga didapat nilai B sebesar 1.388 jam (4 jam x 347 unit). Tahap ketiga menentukan nilai $\mathrm{C}$ yaitu jumlah jam asuhan keperawatan semua pasien selama satu 
tahun. Nilai $\mathrm{C}$ didapat dengan mengalikan nilai $\mathrm{B}$ dengan jumlah hari dalam 1 tahun, sehingga didapatkan nilai C sebesar 506.620 jam (1388 jam x 365).

Selanjutnya tahap empat menentukan nilai $\mathrm{D}$ yaitu jumlah estimasi riil jam asuhan keperawatan yang diperlukan dalam satu tahun. Nilai D didapat dengan mengalikan nilai $\mathrm{C}$ dengan $\mathrm{BOR}$ total yang sebelumnya dibagi dahulu dengan nilai estimasi riil jam asurahan keperawatan sebesar 80. Untuk nilai BOR total didapat dengan cara mengalikan BOR dengan jumlah tempat tidur, sehingga nilai BOR total didapatkan sebesar 229,68 (66,19\% x 347 unit). Setelah mendapatkan nilai BOR total, dilanjutkan dengan mnghitung nilai $\mathrm{D}$ dan didapatkan hasil sebesar 1.454 .506 jam (506.620 jam $\mathrm{x}$ $229,68 / 80)$. Tahap terakhir menentukan nilai E yaitu jumlah perawat yang diperlukan dan didapatkan nilai $\mathrm{E}$ dengan membagi nilai $\mathrm{D}$ dengan jumlah hari efektif dalam 1 tahun.. Sebelum menghitung nilai E, dilakukan penghitungan jumlah hari efektif dalam 1 tahun dan didapatkan hasil sebesar $1878\{(365-52$ hari libur $)$ x 6 jam $\}$. Kemudian dilakukan penghitungan nilai $\mathrm{E}$ dengan hasil sebesar 774,5 orang atau dibulatkan menjadi 775 orang (1.454.506 jam/1878). Sehingga berdasarkan penghitungan metode Formula Nina, jumlah perawat yang diperlukan RSUD dr. Soedono Madiun dengan tingkat BOR $66,19 \%$ adalah 775 orang.

\section{Formula Ilyas}

Metode ini dikembangkan dikarenakan adanya kesulitan dari manajer rumah sakit tentang penghitungan dengan metode Gilles yang mengacu pada beban kerja perawat di Amerika, dianggap kurang pas karena jumlah tenaga yang dibutuhkan jadi lebih kecil sehingga beban kerja perawat tinggi, serta formula dari Lokakarya PPNI yang menghasilkan jumlah perawat lebih banyak. Sehingga formula ini dikembangkan sesuai dengan masukan yang diberikan oleh para praktisi.

Hasil penghitungan kebutuhan tenaga perawat dari metode ini adalah :

$\begin{aligned} \text { Tenaga Perawat } & =\frac{\mathrm{AxB} 365}{255 \mathrm{xjam} \text { kerja/hari }} \\ & =\frac{4 \text { jam } \times(66,19 \% \times 347) \times 365}{255 \times 6 \text { jam }} \\ & =\frac{335.331,78}{1.530} \\ & =219,17 \\ & =219 \text { orang }\end{aligned}$

Keterangan :

A = Jam kerja asuhan keperawatan selama 24 jam

$\mathrm{B}=$ BOR x Jumlah TT

Angka $365=$ Jumlah hari per tahun

Angka $255=$ Hari kerja efektif selama 1 tahun

Jam kerja per hari $=6$ jam

Berdasarkan penghitungan metode Formula Ilyas, jumlah tenaga perawat yang diperlukan RSUD dr. Soedono Madiun dengan tingkat BOR 66,19\% adalah 219 orang. 


\section{PEMBAHASAN}

RSUD dr. Soedono Madiun merupakan Rumah Sakit Pemerintah Provinsi Jawa Timur yang berkedudukan di Kota Madiun. Dalam penghitungan kebutuhan tenaga, RSUD dr. Soedono Madiun mengacu pada Permendagri dan Permenkes. Kondisi ini terkadang membuat penghitungan kebutuhan tenaga sulit dilakukan secara keseluruhan. Hal ini dikarenakan, untuk setiap peraturan memiliki formula penghitungan yang berbeda, sehingga dalam prakteknya RSUD dr. Soedono Madiun melakukan kombinasi penghitungan kebutuhan tenaga.

Dari 2 (dua) metode penghitungan yang digunakan pada penelitian ini, terdapat hasil yang berbeda secara signifikan terhadap penghitungan jumlah tenaga keperawatan di RSUD dr. Soedono Madiun. Perbedaan tersebut berasal dari penghitungan jam kerja perawatan per tahun, dimana untuk Metode Formula Nina, total jam kerja perawatan akan dihitung secara menyeluruh terlebih dahulu baru dikalikan dengan BOR yang ada. Sedangkan pada Metode Formula Ilyas, total jam kerja langsung dikalikan dengan BOR.

Selain itu, perbedaan juga berasal dari pembagi waktu hari efektif kerja per tahun, dimana pada Metode Formula Nina, penghitungan hari kerja efektif didapat dari pengurangan hari di dalam satu tahun dengan hari libur dan langsung dikalikan jam kerja efektif. Sedangkan pada Metode Formula Ilyas, penghitungan hari kerja efektif didapat dari jumlah hari kerja selama 1 tahun dikurangi jumlah cuti dan hari libur dikalikan indeks tiga per empat (3/4). Indeks $3 / 4$ ini berasal dari karakteristik jadwal kerja paramedis rumah sakit pemerintah dan swasta di Indonesia, dimana setelah tiga hari bekerja maka pada hari keempat perawat mendapat libur satu hari.

Bila melihat kondisi tenaga perawat RSUD dr. Soedono Madiun per Januari 2018, diketahui jumlahnya telah mencapai 427 orang, dan masih dianggap kurang memenuhi kebutuhan tenaga dalam layanan keperawatan, maka Metode Formula Nina yang dapat mengakomodir dari kebutuhan perawat di RSUD dr. Soedono Madiun. Namun perlu dipertimbangkan juga dengan kemampuan dari RSUD dr. Soedono Madiun baik secara materiil dan non materiil dalam mengelola tenaga perawat yang jumlahnya mencapai $40 \%$ dari total tenaga yang ada. Sehingga dalam pemenuhan tenaga perawat dapat dilaksanakan secara bertahap sesuai dengan perkembangan dari rumah sakit.

Namun perlu dipertimbangkan pula unsur-unsur dalam penghitungan keakuratan nilai yang dicantumkan, seperti nilai jam perawatan dalam 24 jam dan jam kerja efektif yang disesuaikan dengan kondisi pembagian shift kerja perawat. Sesuai dengan langkah awal perencanaan tenaga perawat yaitu menelaah beban dan bentuk layanan keperawatan yang diberikan (Samodra, 2017). Sehingga metode penghitungan yang akan digunakan lebih peka terhadap kondisi yang ada di RSUD dr. Soedono Madiun

Berdasarkan hasil penghitungan 2 (dua) metode tersebut, faktor kebijakan dari manajemen rumah sakit sangat berpengaruh dalam menentukan metode penghitungan kebutuhan perawat. Aspek-aspek dalam perencanaan tenaga perawat seperti jumlah beban kerja, kategori jenis layanan dan rasio perawat dengan jumlah pasien dan tingkat ketergantungan pasien dapat menjadi pertimbangan dalam pemilihan metode penghitungan. Sebagaimana yang dijelaskan Soesanto \& Ersyad (2019) Perawat dengan beban kerja berat dapat mengalami kelelahan dalam bekerja sehingga berpotensi terjadinya penyimpangan kerja yang akan menurunkan kinerja perawat maupun kualitas layanan. Sebelum memutuskan melakukan penambahan tenaga perawat, manajemen rumah sakit pun dapat mempertimbangkan anggaran rumah sakit dan pola demand 
pasien agar terjadi keseimbangan antara anggaran yang tersedia dengan jumlah pegawai yang dibutuhkan. Pada tenaga perawat yang memiliki beban kerja yang berat, Ningsih (2018) menyebutkan bahwa manajemen rumah sakit perlu melakukan capacity building dan pemberian reward berdasarkan beban kerjanya untuk menjaga komitmen pekerjaan dan mengurangi kejenuhan dalam bekerja.

\section{SIMPULAN}

Terdapat perbedaan hasil penghitungan kebutuhan tenaga perawat pada Metode Formula Nina dan Metode Formula Ilyas. Hasil penghitungan dari metode Formula Nina yang mendekati dengan kebutuhan tenaga perawat RSUD dr. Soedono Madiun saat ini.

\section{SARAN}

Perlu kebijakan manajemen RSUD dr. Soedono Madiun dalam memilih metode penentuan kebutuhan tenaga keperawatan dengan mempertimbangan aspek dalam perencanaan tenaga perawat seperti jumlah beban kerja, kategori jenis layanan dan rasio perawat dengan jumlah pasien dan tingkat ketergantungan pasien.

\section{DAFTAR PUSTAKA}

Kementerian Kesehatan RI. (2017). Situasi Tenaga Keperawatan Indonesia. In Pusat Data dan Informasi Kementerian Kesehatan RI (pp. 1-12). http://www.depkes.go.id/resources/download/pusdatin/infodatin/infodatin perawat 2017.pdf

Nurjanah, S., Sakka, A., \& Paridah, P. (2017). Analisis Beban Kerja Perawat di Instalasi Rawat Inap Rumah Sakit Umum Daerah (RSUD) Kota Kendari Tahun 2016. Jurnal Ilmiah Kesehatan Masyarakat Unsyiah, 2(5), 1-11. https://media.neliti.com/media/publications/186577-ID-analisis-beban-kerjatenaga-perawat-di-i.pdf

Padila, P., Lina, L. F., Febriawati, H., Agustina, B., \& Yanuarti, R. (2018). Home Visit Berbasis Sistem Informasi Manajemen Telenursing. Jurnal Keperawatan Silampari, 2(1), 217-235. https://doi.org/10.31539/jks.v2i1.305

Rizcarachmakurnia, N., Wigati, P., \& Sriatmi, A. (2017). Analisis Beban Kerja dan Kebutuhan Tenaga Perawat di Puskesmas Poncol Kota Semarang. Jurnal Kesehatan Masyarakat Universitas Diponegoro, 5(3), 26-32. https://ejournal3.undip.ac.id/index.php/jkm/article/view/17163

Rizky, W., Darmaningtyas, N., \& Yulitasari, B. I. (2018). Hubungan Jumlah Tenaga Perawat dengan Beban Kerja Perawat Pelaksana di Ruang Rawat Inap Kelas III RSUD Wates. Indonesian Journal of Hospital Administration, 1(1), 38. https://doi.org/10.21927/ijhaa.v1i1.752

Samodra, T. G. (2017). Gambaran Perawat tentang Persepsi Beban Kerja Perawat di Ruang Inap RSUD $d r$. M. Azhari Pemalang. Universitas Diponegoro. http://eprints.undip.ac.id/56621/

Soesanto, D., \& Ersyad, T. (2019). Penghitungan Kebutuhan Tenaga Keperawatan Berdasarkan WISN di RS. Gotong Royong. Journal of Health Sciences, 12(02), 71-81. https://doi.org/10.33086/jhs.v12i02.554 